УДК 634.664.8

\title{
СОСТАВ И СОДЕРЖАНИЕ АНТОЦИАНОВ ЦВЕТКОВ POLYGONUM
} AVICULARE L.

\author{
(C) Э.Э. Джафарова, Л.А. Мустафаева, С.В. Серкеров" \\ Институт ботаники Национальной Академии наук Азербайджана, \\ Бадамдарское шоссе, 40, AZ 1073, Баку (Азербайджан), \\ e-mail: latafat_shamsizade@mail.ru
}

\begin{abstract}
Впервые изучены количественное содержание и качественный состав антоцианов в цветках Polygonum aviculare L., собранных в фазе массового цветения на территории Кусарского района Азербайджанской Республики. Сумму антоцианов получили экстрагированием растительного материала метанолом, содержащим $0,5 \%$ соляной кислоты. Методом двумерной бумажной хроматографии в сумме установили наличие трех антоцианов, индивидуальные антоцианы получили колоночной хроматографией, используя сорбент кислый целлюлозный порошок. Получили три индивидуальных антоциана. Установлено, что два из них являются производными цианидина и один - пеларгонидина. На основании хроматографии, химических и спектральных данных антоцианы идентифицированы как цианидин-3глюкозид, цианидин-3,5-диглюкозид и пеларгонидин-3,5-диглюкозид. В сумме большая часть приходится на долю производных цианидина. Содержание антоцианов в цветках в зависимости от места произрастания изменяется от 720 до 1013 мг\% на сырую массу.

Ключевые слова: Polygonum, антоцианы, бумажная хроматография, спектроскопия.
\end{abstract}

\section{Введение}

Семейство Гречишные Polygonaceae L. охватывает 30 родов и более 750 видов. Гречишник Polygonum L. - один из родов, входящих в это семейство. Род гречишник во флоре Азербайджана представлен 28 видами [1], а по новым данным - 17 видами [2]. Из 28 видов, произрастающих в Азербайджане, наиболее широко распространен горец птичий Polygonum aviculare L.

Известно, что различные органы видов Polygonum L. в народной и научной медицине используются для лечения ряда болезней [3]. Некоторые виды рода являются ценными дубителями [4]. Среди видов рода Polygonum L. наиболее широкое медицинское и пищевое значение имеет горец птичий. В народной медицине трава этого вида в виде настоя применяется при болезнях печени, почек, при заболеваниях желудочно-кишечного тракта, поносе, дизентерии, в качестве вяжущего, а также как кровоостанавливающее и противомалярийное средство [5]. В научной медицине употребляется как вяжущее, общеукрепляющее и диуретическое средство [6]. Трава разрешена к применению в научной медицине как мочегонное средство и при почечных камнях, а препарат «Авикулярен» - при геморроидальных и маточных кровотечениях [7]. Наружно применяют при ушибах и опухолях.

Лекарственные свойства различных органов Polygonum aviculare связаны с их химическим составом. В различных органах растения установлено наличие антрахинонов [8], кумаринов, флавоноидов [9], катехинов [10] и других биологически активных веществ. В литературе отсутствуют сведения о составе и содержании антоцианов. Антоцианы, наряду с Р витаминной активностью, обладают антирадикальной [11],

Джафарова Эльнура Эльдар- диссертант, e-mail: eldar_novruzov@yahoo.co.uk

Мустафаева Латафат Ахад - ведущий научный сотрудник, кандидат биологических наук, e-mail: latafat_shamsizade@mail.ru

Серкеров Сираджеддин Велиевич - главный научный сотрудник, доктор химических наук, e-mail: s.serkerov@mail.ru антиоксидантной [12], антиканцерогенной [13], антимутагенной [14], антивирусной, антибактериальной [15], инсулинсекреторной [16] и интерферониндукторной [17] активностью. Кроме медицины, антоцианы находят применение в пищевой [18-20] и текстильной [21] промышленности.

\footnotetext{
* Автор, с которым следует вести переписку.
} 
Поэтому проблема изыскания антоциансодержащих источников с целью получения натуральных пищевых красителей, медицинских препаратов, пищевых добавок на современном этапе очень актуальна.

\section{Материал и методы}

Материалом для исследования служили свежие цветки Polygonum aviculare L., собранные в фазе массового цветения (в августе 2013 г.).

Сумму антоциановых соединений получали экстрагированием растительного материала (500 г) метанолом, содержащем 0,5\% соляной кислоты. Дальнейшую обработку полученного экстракта провели по методу Э.Н. Новрузова и др. [22].

Для обнаружения антоциановых соединений использовали метод хроматографии на бумаге (FN 16) в системах (об./об.): бутанол - уксусная кислота - вода (4 : $1: 2)$ (I), вода - соляная кислота - уксусная кислота (82: $3: 15)$ (II), «Форестал» (уксусная кислота - соляная кислота - вода $30: 3: 10)$ (III), «Формик» (муравьиная кислота - соляная кислота - вода $5: 2: 3$ ) (IV) и вода - соляная кислота (97:3) (V). Качественный состав суммы антоцианов установили двумерной хроматографией на бумаге в системах I, II, V, а агликонов в системах III и IV. Антоцианы в индивидуальном состоянии получили методом колоночной хроматографии с использованием колонки с кислым целлюлозным порошком [23], применяя в качестве растворителя систему II. Индивидуальные антоцианы очищали рехроматографированием на бумаге в системе II.

Идентификацию веществ проводили по окраске пятен и по максимумам поглощения в видимой области УФ-спектра $[24,25]$. УФ-спектры регистрировали на спектрофотометре Spekol 1500. Для установления числа и положения сахарных остатков использовали метод частичного и полного гидролиза [26-28].

Место присоединения углеводного остатка установили по гипсохромному сдвигу [23], состав и количество сахаров в молекуле антоцианов определяли по Чандлер и Хапперу [26], природу сахаров установили хроматографией на бумаге (система I) со свидетелями. Полный и частичный гидролизы, а также щелочное расщепление антоцианов проводили по Харборну [25] и Чандлер, Хаппер [26].

\section{Обсуждение результатов}

Предварительная двумерная хроматография суммы антоцианов показала, что в сумме антоцианов цветков Polygonum aviculare L. содержится четыре компонента. Содержание одного компонента очень незначительно. Судя по значению $\mathrm{R}_{\mathrm{f}}$, окраске пятен в видимом и УФ-свете, его можно отнести к пеларгонидин-3-глюкозиду. После кислотного гидролиза суммы антоцианов на хроматограмме обнаружено два антоцианидина. Некоторые хроматографические и спектральные данные индивидуальных антоцианидинов представлены в таблицах 1 и 2. На основании полученных хроматографических и спектральных данных и сравнения их с аутентичными образцами, полученными из Rosa L. и Petunia L., выделенные индивидуальные антоцианидины идентифицированы как цианидин и пеларгонидин.

Из суммы антоцианов методом колоночной хроматографии с колонкой, заполненной кислым целлюлозным порошком, используя систему II, получали пять фракций. Хроматография на бумаге в системах I и II показала, что фракции I, III и V содержат по одному компоненту, фракции II и IV являются смесями. Рехроматографией на бумаге в системе II получили три индивидуальных вещества, которые условно обозначили I, II и III.

Некоторые хроматографические и спектральные характеристики выделенных веществ представлены в таблицах 3 и 4 соответственно.

Кислотный гидролиз вещества I через 30 мин приводит к получению агликона, которой по значению $\mathrm{R}_{\mathrm{f}}$ и данных УФ-спектра идентичен с цианидином $[11,12]$.

Таблица 1. Хроматографическая характеристика антоцианидинов

\begin{tabular}{c|c|c|c|c|c}
\hline \multirow{2}{*}{ Антоцианидины } & \multicolumn{3}{|c|}{$R_{\mathrm{f}}$ значения в системах } & \multicolumn{2}{c}{ Окраска пятен } \\
\cline { 2 - 6 } & $\mathrm{I}$ & $\mathrm{III}$ & $\mathrm{IV}$ & в видимом свете & в УФ-свете \\
\hline Антоцианидин 1 & 0,57 & 0,49 & 0,22 & пурпурный & розово-лиловый \\
Антоцианидин 2 & 0,81 & 0,68 & 0,32 & красный & оранжево-красный \\
\hline
\end{tabular}

Таблица 2. Спектральная характеристика выделенных антоцианидинов

\begin{tabular}{c|c|c|c|c}
\hline \multirow{2}{*}{ Антоцианидины } & \multicolumn{3}{|c|}{ Максимум поглощения, нм } & $\mathrm{E}_{440} / \mathrm{E}_{\max }$, \\
\cline { 2 - 4 } & метанол, содержащий 0,1\% НСl & этанол, содержащий 0,1\% $\mathrm{HCl}$ & метанол $+3 \% \mathrm{AlCl}_{3}$ & 19 \\
\hline Антоцианидин 1 & 535 & 545 & 545 & 19 \\
Антоцианидин 2 & 520 & 530 & 520 & 19 \\
\hline
\end{tabular}


Таблица 3. Хроматографическая характеристика индивидуальных антоцианов

\begin{tabular}{c|c|c|c|c|c}
\hline \multirow{2}{*}{ Вещество } & \multicolumn{3}{|c|}{$R_{\mathrm{f}}$ значения в системах } & \multicolumn{2}{c}{ Окраска пятен } \\
\cline { 2 - 5 } & I & II & III & в видимом свете & в УФ-свете \\
\hline Вещество I & 0,36 & 0,25 & 0,06 & фуксиновый & тускло-фуксиновый \\
Вещество II & 0,41 & 0,29 & 0,19 & фуксиновый & серо-фуксиновый \\
Вещество III & 0,44 & 0,31 & 0,20 & оранжево-красный & тускло-красный \\
\hline
\end{tabular}

Таблица 4. Спектральная характеристика индивидуальных антоцианов

\begin{tabular}{|c|c|c|c|c|}
\hline \multirow{2}{*}{ Вещество } & \multicolumn{3}{|c|}{ Максимум поглощения, нм. } & \multirow{2}{*}{$\begin{array}{c}\mathrm{E}_{440} / \mathrm{E}_{\max } \\
\%\end{array}$} \\
\hline & метанол, содержащий 0,1\% HCl & этанол, содержащий $0,1 \% \mathrm{HCl}$ & этанол $+\mathrm{AlCl}_{3}$ & \\
\hline Вещество I & 280,520 & 535 & 548 & 22 \\
\hline Вещество II & 281,528 & 536 & 542 & 12 \\
\hline Вещество III & 270,524 & 512 & 520 & 38 \\
\hline
\end{tabular}

В сахарной части гидролизата обнаружено вещество, идентифицированное по результатам хроматографии на бумаге со свидетелем с D-глюкозой.

Следовательно, исследуемое вещество является моногликозидом цианидина (цианидин-3-глюкозид).

Результаты окисления вещества І перекисью водорода свидетельствуют о нахождении сахарного остатка при $\mathrm{C}_{3}$ в молекуле агликона.

Вещество II при полном кислотном гидролизе известным способом образует агликон, идентичный цианидину, и глюкозу в соотношении $1: 2$. Из литературы известно, что 3-диглюкозиды и 3,5-диглюкозиды распознаются в результате проведения частичного гидролиза. При этом сначала образуются моногликозиды, затем агликон и сахар [12]. При частичном гидролизе второго вещества через 30 мин в растворе был обнаружен только исходный антоциан (вещество II), а через 60 мин при хроматографировании гидролизата в системе II обнаружено два пятна с $R_{\mathrm{f}} 0,06$ и 0,10 соответственно. По хроматографическим данным $R_{\mathrm{f}}$ пятен и их окраске в видимом и УФ-свете (в отличие от 3-глюкозида, в 5-глюкозиде в хроматограмме флюоресцирует желтой окраской) установлено, что первое пятно соответствует цианидин-3глюкозиду, а второе - цианидин-5-глюкозиду.

На основании результатов хроматографических, спектральных анализов, кислотного гидролиза вещества II и сравнения его с аутентичным образцом, а также по литературным данным оно идентифицировано как цианидин-3,5-диглюкозид.

Вещество III при полном кислотном гидролизе образует агликон и глюкозу в соотношении $1: 2$. Агликон вещества III имеет $R_{\mathrm{f}} 0,68$ (система III) и 0,32 (система IV), $\lambda_{\max }$ в УФ-спектре - 520 (в растворе, содержащем $0,1 \% \mathrm{HCl}$ ) и 530 (в этаноле, содержащем 0,1\% $\mathrm{HCl}$ ). Сравнение полученных данных хроматографических и спектральных анализов с аутентичными образцами и литературными данными позволило идентифицировать агликон вещества III как пеларгонидин. В сахарной части гидролизата обнаружен сахар (по результатам хроматографии на бумаге со свидетелем), идентичный с D-глюкозой.

На основании данных хроматографии, УФ-спектров, а также сравнения продуктов полного и частичного гидролиза с аутентичными образцами и литературными данными $[9,12]$ вещество III идентифицировано как пеларгонидин 3,5-диглюкозид.

Денситометрические исследования хроматограммы суммы антоцианов показали, что соотношение компонентов в сумме неодинаковое: наибольшее содержание приходится на долю производных цианидина.

Изучение количественного содержания антоцианов в цветках исследованного растения показало, что в зависимости от места произрастания оно изменяется в пределах 0,720-1013 мг\%. Состав и содержание антоцианов в цветках Polygonum aviculare установлены впервые.

\section{Выводы}

1. Впервые установлены качественный состав и количественное содержание антоцианов в цветках Polygonum aviculare L. Методом двумерной хроматографии установлено, что в состав суммы антоцианов входят два производных цианидина и один - пеларгонидина.

2. Из суммы антоцианов выделены три индивидуальных антоциана, которые на основании хроматографических и спектральных анализов идентифицированы как цианидин-3-глюкозид, цианидин-3,5диглюкозид и пеларгонидин-3,5-диглюкозид.

3. Установлено, что содержание антоцианов в цветках Polygonum aviculare L. в зависимости от места произрастания варьирует в пределах 720-1013 мг. В сумме наибольшее содержание приходится на долю производных цианидина. 


\section{Список литературы}

1. Рзазаде Р.Я. Род Гречишник Polygonum L. // Флора Азербайджана. Баку, 1952. T. III. 166 с.

2. Мехтиева Н.П. Биоразнообразие лекарственной флоры Азербайджана. Баку, 2011. 186 с.

3. Растительные ресурсы СССР. Л., 1985. 258 с.

4. Михайлова В.Л. Дубильные растения Казахстана. Алма-Ата, 1968. 326 с.

5. Йорданов Д., Николов П., Бройчинов А. Фитотерапия. София, 1970. 342 с.

6. Турова А.Д. Лекарственные растения СССР и их применение. М., 1974. 424 с.

7. Скляревский Л.Я., Губанов И.А. Лекарственные растения в быту. М., 1989. 272 с.

8. Hagnauer R. Chemotaxonomie der Pflanzen. Basel, Stuttgart, 1968. Bd. 5. 506 s.

9. Хворост П.П., Комиссаренко Н.Ф. Флавоноиды Polygonum aviculare // Химия природных соединений. 1980. №6. C. 840.

10. Haverland F. Polygonum aviculare L. // Pharmazie. 1963. Jahrg 18. N1. Pp. 59-67.

11. Gulcin I., Boroshvili D., Gepdiremen A. Antiradical and antioxidant activity of total anthocyanins from Perilla pankinensis decne // J. Ethnopharmacol. 2005. Vol. 10. N1-3. Pp. 287-293.

12. Adhikari D., Fracis J., Schutzki et al. Quantificatin and caracterication of cyclo-oxygenase and lipid perokidation inhibitory anthosyanins in fruits of Amelanchier // Phytochem. Anal. 2005. Vol. 16, N3. Pp. 175-180.

13. Bagchi D., Sen C., Bagchi V., Atalay M. Anthiangiogenic, antioxidant and anticansirogenic properties of novel anthocyanin-rich berry extract formula // Biochemistry (Mosc.), 2004. Vol. 69, N1. Pp. 75-80.

14. Edenharden R., Von Petersdorfi J., Baucher R. Antimutagenic effects of flavonoids, chalconees, anthocyanines and structurally related compounds on the activity of 2-amino-3-methyl imidase (4,5-guinoline) (IQ) and other heterocyclic amine mutagens from cooked food // Mutat. Res. 1993. Vol. 287. Pp. 261-279.

15. Leitao D., Polizello A., Ito I. et al. Antibacterial screening of anthocyanic and proanthocyanic fractions from cranberry juice // J. Med. Food. 2005. Vol. 8, N1. Pp. 36-40.

16. Jayaprakasam B., Vareed S., Olsen L., Naur M. Insulin secretion by bioactive anthocyanins and anthocyanidins present in fruits // J. Agric. Food Chem. 2005. Vol. 53, N1. Pp. 28-31.

17. А.с. 1506667 (СССР). Индуктор интерферона / Э.Н. Новрузов, З.А. Лазымова, Т. Асадуллаев и др. 1987.

18. А.с. 790753 (СССР). Способ получения пищевого красителя из растительного сырья / Э.Н. Новрузов, С.М. Асланов, Л.А. Шамсизаде и др. 1980.

19. А.с. 1705324 (СССР). Способ получения антоциановогопищевого красителья / Э.Н. Новрузов, М.Т. Фахрадова, Л.А. Шамсизаде, Т. Гаджиева. 1991.

20. Новрузов Э.Н. Перспективные пищевые красительные растения Азербайджана // Материалы I Всеросс. конф. по ботаническому ресурсоведению. СПб., 1996. С. 202-203.

21. Cardon D. Polyphenols and natural dyes: a historian contemplates chemistry. Polyphenols-96. Borcleaux, 1995. Pp. 45-79.

22. Новрузов Э., Ибадов О. Антоцианы цветков рода Tulipa L. // Химия природных соединений. 1986. №2. С. 246.

23. А.с. 1705324 (СССР). Способ получения антоцианового пищевого красителя / Э.Н. Новрузов, М.Т. Фахрадова, Л.А. Шамсизаде, Т. Гаджиева. 1991.

24. Harborne J. Spectral methods of characterizing anthocyanins // J. Bichem. 1958. Vol. 70, N1. Pp. $22-28$.

25. Harborne J. The Chromatographic Identification of anthocyanin pigments // J. Chromatogr. 1958. N1. Pp. $473-488$.

26. Chandler E., Harper K. Identification of saccharides in anthocyanins and other flavonoids // J. Aust. Chem. 1961. Vol. 14, N4. P. 586.

27. Abe Y., Nayashi K. Studies on anthocyanins. XXIX. Further studies on paper chromatography on anthocyanins involving an examination of glycoside types by partial hydrolises // Bot. Mag. (Tokyo). 1956. Vol. 69. P. 577.

28. Новрузов Э.Н. Пигменты репродуктивных органов растений и их значение. Баку, 2010. 308 с.

Поступило в редакцию 27 декабря 2015 г.

После переработки 30 марта 2016 г. 
Jafarova E.E., Mustafayeva L.A., Serkerov S.V. ${ }^{*}$ COMPOSITION AND CONTENT OF ANTHOCYANINS OF THE POLYGONUM AVICULARE L. FLOWERS

Institute of Botany of Azerbaijan National Academy of Sciences, Badamdar shosse, 40, Baku, AZ 1073 (Azerbaijan), e-mail: latafat_shamsizade@mail.ru

For the first time studied the quantitative and qualitative composition of the content of anthocyanins in flowers Polygonum aviculare L., collected in the phase of mass flowering in the territory of Gusar region of Azerbaijan Republic. The amount of anthocyanin plant material obtained by extraction with methanol containing $0,5 \%$ hydrochloric acid. The method of two-dimensional paper chromatography in the amount of 3 established the presence of anthocyanins, individual anthocyanins obtained by column chromatography using a sorbent acidic cellulose powder. Get 3 individual anthocyanin. It was found that two of them are derived from one of cyanidin and pelargonidin. Based on chromatography, chemical and spectral data was determined by their nature and anthocyanins were identifirovany both cyaniding-3-glucoside, cyanidin-3,5-diglucoside and pelargonidin-35 diglucoside. In total, the highest content accounted for derivatives of cyanidin. The content of anthocyanins in flowers, depending on the place of growth varies from 720 to $1013 \mathrm{mg} \%$ on wet weight.

Keywords: Polygonum, anthocyanins, paper chromatography, spectroscopy.

\section{References}

1. Rzazade R.Ja. Pod Grechishnik - Polygonum L. Flora Azerbajdzhana. [Polygonum L. Flora of Azerbaijan]. Baku, 1952, vol. III, 166 p. (in Russ.).

2. Mehtieva N.P. Bioraznoobrazie lekarstvennoj flory Azerbajdzhana. [Biodiversity of medicinal flora of Azerbaijan]. Baku 2011, 186 p. (in Russ.).

3. Rastitel'nye resursy SSSR. [Plant resources of the USSR]. Leningrad, 1985, 258 p. (in Russ.).

4. Mihajlova V.L. Dubil'nye rastenija Kazahstana. [Tanning plant in Kazakhstan]. Alma-Ata, 1968, 326 p. (in Russ.).

5. Jordanov D., Nikolov, Brojchinov A. Fitoterapija. [Phytotherapy]. Sofia, 1970, 342 p. (in Russ.).

6. Turova A.D. Lekarstvennye rastenija SSSR $i$ ih primenenie. [Medicinal plants of the USSR and their application]. Moscow, 1974, 424 p. (in Russ.).

7. Skljarevskij L.Ja., Gubanov I.A. Lekarstvennye rastenija $v$ bytu. [Medicinal plants in the home]. Moscow, 1989, 272 p. (in Russ.).

8. Hagnauer R. Chemotaxonomie der Pflanzen. Basel, Stuttgart, 1968. Bd. 5. 506 s.

9. Hvorost P.P., Komissarenko N.F. Himija prirodnyh soedinenij, 1980, no. 6, pp. 840. (in Russ.).

10. Haverland F. Pharmazie, 1963, Jahrg 18, no. 1, pp. 59-67.

11. Gulcin I., Boroshvili D., Gepdiremen A. J. Ethnopharmacol., 2005, vol. 10, no. 1-3, pp. 287-293.

12. Adhikari D., Fracis J., Schutzki et al. Phytochem. Anal., 2005, vol. 16, no. 3, pp. 175-180.

13. Bagchi D., Sen C., Bagchi V., Atalay M. Biochemistry (Mosc.), 2004, vol. 69, no. 1, pp. 75-80.

14. Edenharden R., Von Petersdorfi J., Baucher R. Mutat. Res., 1993, vol. 287, pp. 261-279.

15. Leitao D., Polizello A., Ito I. et al. J. Med. Food., 2005, vol. 8, no. 1, pp. 36-40.

16. Jayaprakasam B., Vareed S., Olsen L., Naur M. J. Agric. Food Chem., 2005, vol. 53, no. 1, pp. 28-31.

17. Certificate of authorship 1506667 (USSR). 1987. (in Russ.).

18. Certificate of authorship 790753 (USSR). 1980. (in Russ.).

19. Certificate of authorship 1705324 (USSR). 1991. (in Russ.).

20. Novruzov Je.N. Mater. I Vserossijskoj konf. po botanicheskomu resursovedeniju. [Materials of I All-Russian conference on botanical resources]. St. Petersburg, 1996, pp. 202-203. (in Russ.).

21. Cardon D. Polyphenols and natural dyes: a historian contemplates chemistry. Polyphenols-96. Borcleaux, 1995, pp. 45-79.

22. Novruzov Je., Ibadov O. Himija prirodnyh soedinenij, 1986, no. 2, p. 246. (in Russ.).

23. Certificate of authorship 1705324 (USSR). 1991. (in Russ.).

24. Harborne J. J. Bichem., 1958, vol. 70, no. 1, pp. 22-28.

25. Harborne J. J. Chromatogr., 1958, no. 1, pp. 473-488.

26. Chandler E., Harper K. J. Aust. Chem., 1961, vol. 14, no. 4, p. 586.

27. Abe Y., Nayashi K. Bot. Mag. (Tokyo), 1956, vol. 69, p. 577.

28. Novruzov Je.N. Pigmenty reproduktivnyh organov rastenij $i$ ih znachenie. [Pigments reproductive organs of plants and their importance]. Baku, 2010, 308 p. (in Russ.).

Received December 27, 2015

Revised March 30, 2016

\footnotetext{
* Corresponding author.
} 
